\title{
Digestibilidade de dietas contendo resíduo úmido de mandioca em substituição ao milho para tourinhos em terminação
}

\section{José Jorge dos Santos Abrahão1, Ivanor Nunes do Prado², Daniel Perotto ${ }^{1}$, Lúcia Maria Zeoula$^{2}$, José Antônio Cogo Lançanova ${ }^{1}$, Simony Marta Bernardo Lugão ${ }^{1}$}

${ }^{1}$ Instituto Agronômico do Paraná.

2 Departamento de Zootecnia da Universidade Estadual de Maringá.

\begin{abstract}
RESUMO - Avaliou-se a influência da substituição do milho pelo resíduo úmido de mandioca nos coeficientes de digestibilidade dos nutrientes e na porcentagem de NDT e EM (em Mcal $/ \mathrm{kg}$ ) de dietas para tourinhos em terminação. Foram utilizados 20 animais cruzados ( $1 \frac{1}{2}$ e 3/4 Europeu x Zebu) com 24 meses de idade e peso médio de $532 \mathrm{~kg}$, provenientes de um ensaio de desempenho com as mesmas dietas deste ensaio, distribuídos em delineamento completamente casualizado, com cinco tratamentos e quatro repetições. Os tratamentos constaram de cinco dietas contendo silagem de sorgo como volumoso e 0 , $25,50,75$ e $100 \%$ de resíduo de mandioca em substituição ao milho do concentrado. As dietas não diferiram significativamente quanto aos coeficientes de digestibilidade $(\mathrm{MS}=65,42 \%, \mathrm{~PB}=68,30 \% ; \mathrm{EE}=67,72 \%, \mathrm{FDN}=49,58 \%, \mathrm{FDA}=50,71 \%$, $\mathrm{CNF}=81,79 \%$ ) e aos teores de NDT $=65,47 \%$ e $\mathrm{EM}=2,36 \mathrm{Mcal} / \mathrm{kg}$. Somente o coeficiente de digestibilidade aparente dos CHO diferiu entre as $\operatorname{dietas}\left(\hat{\mathrm{Y}}=-0,0684 \mathrm{~N}+0,0015 \mathrm{~N}^{2}+63,756 ; \mathrm{R}^{2}=0,9122\right)$. A utilização do resíduo de mandioca em substituição ao milho, à exceção dos $\mathrm{CHO}$, não alterou os coeficientes de digestibilidade dos nutrientes estudados.
\end{abstract}

Palavras-chave: confinamento, digestibilidade, energia, gado de corte, subproduto da mandioca

\section{Replacing corn grain with a wet byproduct from cassava starch extraction on apparent digestibility of nutrients in beef cattle}

\begin{abstract}
Twenty crossbred bulls (1/2 and 3/4 Bos taurus $x$ Bos indicus) averaging 24 months of age and $532 \mathrm{~kg}$ of body weight at the beginning of the experiment were used. Animals were randomly assigned to five treatments (four replicates/treatment) in a completely randomized design to evaluate the effect of replacing corn grain with a wet byproduct of cassava starch extraction on apparent digestibility of nutrients. Bulls were fed diets containing sorghum silage and one of the following levels of cassava byproduct in the concentrate: $0,25,50,75$ or $100 \%$. No significant differences were observed for apparent digestibility of nutrients that averaged: $65.42 \%$ (dry matter), 68.30\% (crude protein), 67.72\% (ether extract), $49.58 \%$ (neutral detergent fiber), $50.71 \%$ (acid detergent fiber), and $81.79 \%$ (nonfiber carbohydrates). The contents of TDN $(65.47 \%)$ and $\mathrm{ME}(2.36 \mathrm{Mcal} / \mathrm{kg})$ also did not differ among diets. Only apparent digestibility of total carbohydrates differed across diets: $\hat{\mathrm{Y}}=-0.0684 \mathrm{~N}+0.0015 \mathrm{~N}^{2}+63.756 ; \mathrm{R}^{2}=0.9122$. Replacing corn grain with cassava byproduct did not change apparent digestibility of nutrients, except for total carbohydrates.
\end{abstract}

Key Words: beef cattle, cassava byproduct, digestibility, energy, feeding, feedlot

\section{Introdução}

Na produção intensiva de bovinos, a alimentação é responsável pela maior parte dos custos variáveis, determinando, na maioria das situações, a viabilidade econômica do empreendimento agropecuário. Assim, tem sido constante na pecuária de corte a procura por alimentos alternativos que permitam a substituição de alimentos usuais por outros de menor custo. Portanto, é fundamental o conhecimento das características do alimento, permitindo estabelecer critérios para sua inclusão nas dietas dos animais, maximizando o potencial digestivo e possibilitando ao animal a manifestação de seu potencial genético e a conseqüente otimização da utilização do alimento para funções produtivas.

Existe uma variedade de alimentos que podem ser utilizados em dietas para ruminantes, sem comprometer o desempenho, possibilitando redução nos custos. Entretanto, é necessário o conhecimento da composição químicobromatológica, da interação dos alimentos e dos produtos finais do processo digestivo envolvendo o animal hospedeiro e os microrganismos do trato digestivo, bem como do uso desses metabólitos, permitindo a adequada utilização desses alimentos em dietas para animais. 
Entre os subprodutos resultantes da industrialização da mandioca, o resíduo úmido da extração da fécula é um dos mais promissores para a alimentação de bovinos, em razão da abundância nas regiões produtoras, da composição bromatológica e do custo. Mesmo após a extração do amido, o material descartado pelas indústrias de fécula apresenta teor elevado de amido residual, médio de fibra e baixo de MS e proteína. A composição média desse resíduo, após a secagem, segundo Cereda (1994), é de $9,52 \%$ de umidade, $0,66 \%$ de cinzas, $63,85 \%$ de amido, $0,83 \%$ de lipídios e $0,32 \%$ de nitrogênio.

A composição química dos resíduos da industrialização da mandioca assemelha-se à das raízes, com elevados teores de carboidratos não-estruturais (Campos Neto \& De Bem, 1995). Enquanto a raiz apresenta $94 \%$ de carboidratos, os resíduos da extração da fécula possuem até $75 \%$ de amido residual (Cereda, 1994), o que os caracteriza como alimentos concentrados energéticos. Essa característica foi confirmada por Melotti (1972), que determinou o valor energético dos principais resíduos da industrialização da mandioca: $74,83 \%$ de NDT para o farelo de bagaço; $76,53 \%$ para o farelo de raspas; $76,69 \%$ para o farelo de farinha de mesa; e 70,64\% para o farelo de varredura e lavador.

A alta degradabilidade do amido é determinante do valor energético desses alimentos. De acordo com Zeoula et al. (1999), para taxa de passagem de 5\% hora, a degradabilidade efetiva do amido da raspa de mandioca $(79,1 \%)$ foi maior que a do milho $(57,8 \%)$ e a do sorgo $(67,6 \%)$ e menor que a do triticale $(98,4 \%)$ e do farelo de trigo $(98,8 \%)$. Maiores coeficientes de digestibilidade aparente e ruminal do amido e da MS da mandioca foram observados por Caldas Neto et al. (2000), que compararam dietas à base de farinha de varredura, raspa de mandioca e milho. Nesse experimento, também foram observadas menor digestibilidade ruminal da proteína, menor concentração de amônia e maior eficiência de síntese microbiana de proteína para as dietas com mandioca, sugerindo melhor sincronização na disponibilidade da energia e do nitrogênio no rúmen.

A substituição do milho desintegrado com palha e sabugo por raspa de mandioca em diferentes níveis de substituição foi estudada por Castro \& Silva (1994), que avaliaram rações para bovinos. O resultado foi aumento linear na digestibilidade da MS e da EB, mas não da proteína, quando se elevaram os níveis de raspa nas dietas. Lorenzoni \& Mella (1994) estudaram os efeitos da inclusão do resíduo da produção de farinha, denominado casquinha, em substituição ao milho desintegrado com palha e sabugo em rações para bovinos em confinamento, e concluíram que esse subproduto poderia ser usado em até $45 \%$ da dieta total.
Esses autores observaram que o coeficiente de digestibilidade aparente da MS da ração total foi influenciado pelo aumento dos níveis de casquinha, melhorando até $12 \%$ com a substituição total do milho desintegrado com palha e sabugo pela casquinha. Os ganhos de peso foram semelhantes entre os tratamentos e variaram de 0,74 a $0,86 \mathrm{~kg} / \mathrm{animal} /$ dia. Martins et al. (2000) estudaram a inclusão de casca de mandioca em substituição ao milho e determinaram maiores valores de digestibilidade para os nutrientes nas dietas com casca em relação àquela com milho.

O objetivo neste trabalho foi determinar os coeficientes de digestibilidade de MS, PB, EE, FDN, FDA, CHO e CNF, bem como as porcentagens de NDT e EM de dietas com diferentes níveis de substituição do milho por resíduo de mandioca para bovinos de corte em terminação.

\section{Material e Métodos}

O experimento foi realizado na Estação Experimental de Paranavaí, do Instituto Agronômico do Paraná - IAPAR, e teve início em novembro de 2001 . Foram utilizados 20 animais mestiços ( $1 / 2$ Europeu $3 / 4 \mathrm{Zebu}$ ) não-castrados com 25 meses de idade e peso médio de $532 \mathrm{~kg}$, pertencentes ao rebanho da estação experimental, oriundos de um projeto de cruzamento. Os animais haviam sido utilizados anteriormente em um experimento de desempenho no qual foram avaliadas as mesmas dietas. Foram mantidos em baias individuais $\left(28 \mathrm{~m}^{2}\right.$ de piso de concreto, cocho de alvenaria coberto, com $60 \mathrm{~cm}$ de profundidade e $3 \mathrm{~m}$ de comprimento e bebedouro), sob o mesmo tratamento ao qual estavam submetidos anteriormente. A quantidade de alimento foi ajustada de modo que, no período de avaliação da digestibilidade, a proporção fornecida correspondesse a 95\% do consumo determinado no experimento anterior.

Os tratamentos propostos consistiram de cinco dietas experimentais, compostas de silagem $(26,20 \%$ de MS) de sorgo forrageiro (AG $2002{ }^{\circledR}$ ), como volumoso, e concentrado à base de milho em grão e/ou resíduo úmido de mandioca (20,71\% de MS), farelo de soja, uréia, vitaminas, minerais e aditivos. A composição média dos alimentos utilizados na formulação das dietas é apresentada na Tabela 1.

As dietas foram formuladas para que a primeira tivesse o concentrado à base de milho e as demais, 25, 50, 75 e 100\% de resíduo de mandioca (com base na MS) em substituição ao milho (Tabela 2). Os concentrados nos quais o milho foi substituído apresentaram menor valor energético, em razão do menor teor de energia do resíduo de mandioca. Para compensar este menor valor energético, a porcentagem dos 
concentrados nas dietas experimentais foi aumentada proporcionalmente, de acordo com o peso corporal e os níveis de substituição, conforme a seguir: 0-1,05;25-1,07; 50-1,1; 75-1,14 e 100\%-1,18\% do peso corporal em MS/animal/dia (considerando um consumo total de MS de 2,1\% do peso corporal, determinado no início do experimento).

Os animais foram alimentados duas vezes ao dia, às 9 e $16 \mathrm{~h}$, registrando-se as quantidades de alimento fornecido e de sobras. As dietas, enriquecidas com monensina sódica (30 mg/kg de MS da dieta) e suplemento vitamínico, foram calculadas segundo o AFRC (1993), de forma a permitir ganho de peso corporal de 1,3 kg/animal/ dia (Tabela 2).

Os animais tinham à disposição $\mathrm{MM}$, com a seguinte composição por kg do produto: $\mathrm{Zn}=5.000 \mathrm{mg}, \mathrm{Cu}=2.000 \mathrm{mg}$, $\mathrm{Co}=30 \mathrm{mg}, \mathrm{Se}=67 \mathrm{mg}, \mathrm{I}=155 \mathrm{mg}$ e Na$=387 \mathrm{~g}$.

Os níveis de Ca e P nas dietas (Tabela 3) foram calculados segundo o NRC (1996).

A coleta total de fezes foi feita diretamente do piso, imediatamente após o animal defecar, por um período de seis dias, registrando-se a excreção diária por animal e coletando-se amostra proporcional à produção total de fezes, além de amostras dos alimentos, que foram congeladas a $-18^{\circ} \mathrm{C}$ para, posteriormente, formar uma amostra composta por animal. Os alimentos e as fezes foram submetidos à determinação dos teores de $\mathrm{MS}, \mathrm{MO}, \mathrm{PB}, \mathrm{FB}, \mathrm{EE}$, ENN, CIN, FDN e FDA, conforme metodologia descrita por Silva \& Queiroz (2002). Os CHO e CNF foram determinados conforme descrição de Hall (2001). Os teores de NDT e EM foram calculados segundo Sniffen et al. (1992): $\mathrm{NDT}=(\mathrm{PBD}+\mathrm{CHOTD})+2,25$ (EED), em que PBD, CHOTDe EED significam \% de $\mathrm{PB}$ digestível, $\mathrm{CHO}$ digestíveis e EE digestível. Para o cálculo da EM, considerou-se que $1 \mathrm{~kg}$ de NDT equivale a 4,409 Mcal de ED e, para a transformação em EM, utilizou-se o valor de $82 \%$ de eficiência de utilização daED, conforme o NRC (1996). O coeficiente de digestibilidade aparente da MS e dos demais nutrientes foi estimado segundo Coelho da Silva \& Leão (1979):

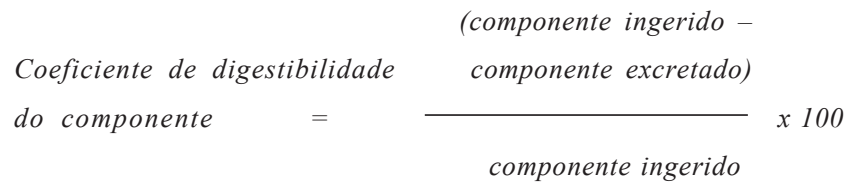

As proporções entre os concentrados e o volumoso determinadas durante o ensaio de digestibilidade foram diferentes do previsto na metodologia, em virtude da redução na ingestão total, ocasionada pela variação no consumo do volumoso, visto que a quantidade de concentrado era previamente determinada. Desse modo, a composição das dietas (Tabela 3 ) indica que os valores de PB variaram conforme o consumo de volumoso, o que provocou alterações na porcentagem de $\mathrm{PB}$, em razão de sua maior porcentagem no concentrado.

Os valores de EE e CNF decresceram com o aumento da participação do resíduo, enquanto os de FDN, FDA e CHO foram maiores.

$\mathrm{O}$ delineamento experimental foi o inteiramente casualizado, com cinco tratamentos e quatro repetições. Os dados foram submetidos às análises de variância e regressão e as diferenças estatísticas, avaliadas pelo teste $\mathrm{F}$ a 5\%, utilizando-se o Sistema de Análises Estatísticas e Genéticas - SAEG (UFV, 1997), de acordo com os modelos:

Análise de variância:

$$
\mathrm{Y}_{\mathrm{ij}}=\mu+\mathrm{t}_{\mathrm{i}}+\mathrm{e}_{\mathrm{ij}}
$$

em que: $Y_{i j}=$ observação no animal $j$ submetido ao tratamento $i ; \mu=$ constante geral; $t_{i}=$ efeito do tratamento $i$; $\mathrm{i}=1, \ldots, 5 ; \mathrm{e}_{\mathrm{ij}}=$ erro aleatório associado a cada observação $\mathrm{Y}_{\mathrm{ij}}$.

Análise de regressão:

$$
Y_{i j}=\mu+b_{1} c+b_{2} c^{2}+a_{i j}
$$

em que: $\mathrm{Y}_{\mathrm{ij}}=$ resposta; $\mu=$ média geral da resposta; $\mathrm{b}_{1}=$ coeficiente de regressão linear de $\mathrm{Y}$ sobre $\mathrm{X}$; $\mathrm{b}_{2}=$ coeficiente de regressão quadrático de $\mathrm{Y}$ sobre $\mathrm{X}$; $\mathrm{c}=$ nível de substituição $(\mathrm{i}=1,2, \ldots, 5$, em que $1=0 \%$ de

Tabela 1 - Teores médios de PB, EE, CIN, ENN, FDN, FDA, CNF, CHO, Ca e P dos concentrados e da silagem de sorgo (\% na MS)

\begin{tabular}{|c|c|c|c|c|c|c|c|c|c|c|}
\hline $\begin{array}{l}\text { Componente } \\
\text { Ingredient }\end{array}$ & $\begin{array}{r}\mathrm{PB} \\
C P\end{array}$ & EE & $\begin{array}{l}\text { CIN } \\
\text { Ash }\end{array}$ & $\begin{array}{l}\text { ENN } \\
N F E\end{array}$ & $\begin{array}{l}\text { FDN } \\
N D F\end{array}$ & $\begin{array}{l}\mathrm{FDA} \\
A D F\end{array}$ & $\begin{array}{l}\mathrm{CNF} \\
N F C\end{array}$ & $\begin{array}{l}\mathrm{CHO} \\
\mathrm{CHO}\end{array}$ & $\mathrm{Ca}$ & $P$ \\
\hline $\begin{array}{l}\text { Resíduo de mandioca } \\
\text { Cassava byproduct }\end{array}$ & 1,92 & 0,29 & 1,81 & 79,59 & 30,50 & 22,66 & 65,48 & 95,98 & 0,32 & 0,05 \\
\hline $\begin{array}{l}\text { Milho grão } \\
\text { Corn grain }\end{array}$ & 10,59 & 4,82 & 1,49 & 80,92 & 16,33 & 3,78 & 66,77 & 83,10 & 0,03 & 0,26 \\
\hline $\begin{array}{l}\text { Farelo de soja } \\
\text { Soybean meal }\end{array}$ & 49,18 & 2,59 & 7,30 & 33,91 & 13,34 & 9,21 & 27,59 & 40,93 & 0,64 & 0,31 \\
\hline
\end{tabular}

Table 1 - Mean contents of CP, EE, ash, NFE, NDF, ADF, NFC, CHO, Ca, and P of concentrate ingredients and sorghum silage (\% DM) 
Tabela 2 - Composição percentual e teores de MO, PB, EE, FDN, FDA, CHO, CNF, Ca e P dos concentrados (\% na MS) Table 2 - Ingredient composition and contents of OM, CP, EE, NDF, ADF, CHO, NFC, Ca, and $P$ of the concentrates (DM\%)

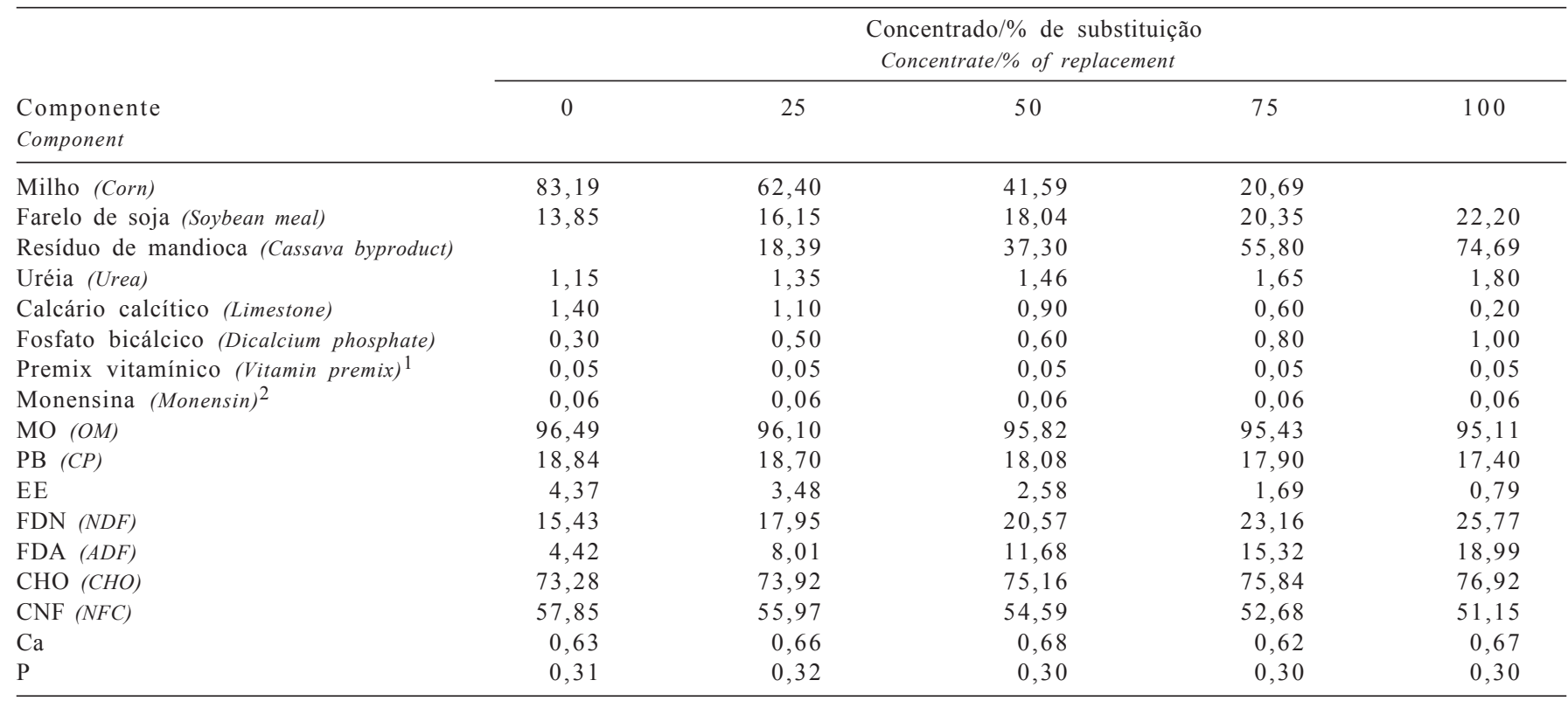

${ }^{1}$ Rovimix $^{\circledR}$ Lab. Roche: vitamina $A=20.000 .000$ UI, vitamina D3 $=2.000 .000$ UI, Vitamina $E=80.000$ UI por kg do produto

2 Rumensin ${ }^{\circledR}$ Laboratório Elanco: $100 \mathrm{mg}$ de monensina por grama do produto.

1 Rovimix ${ }^{\circledR}$ Roche Laboratories: vitamin A 20.000.000 IU, vitamin D3 2.000.000 IU, Vitamin E 80.000 IU per kg of product.

2 Rumensin ${ }^{\circledR}$ Elanco Laboratories: $100 \mathrm{mg}$ of monensin pergram of product.

Tabela 3 - Porcentagem de silagem e concentrado e composição em MO, PB, EE, FDN, FDA, CHO, CNF, Ca e P das dietas experimentais (\% na MS)

Table 3 - $\quad$ Proportion of silage and concentrate in the experimental diets and contents of OM, CP, EE, NDF, ADF, CHO, and NFC

\begin{tabular}{lrrrrr}
\hline & \multicolumn{5}{c}{$\begin{array}{c}\text { Dieta/ \% de substituição } \\
\text { Diet/ \% of replacement }\end{array}$} \\
\cline { 2 - 6 } & \multicolumn{1}{c}{0} & \multicolumn{1}{c}{25} & \multicolumn{1}{c}{50} & \multicolumn{1}{c}{75} & 100 \\
\hline Silagem de sorgo (\%) & 44,84 & 39,87 & 42,45 & 39,60 & 41,44 \\
Sorghum silage & & & & & \\
Concentrado (\%) & 55,16 & 60,13 & 57,55 & 60,40 & 58,56 \\
Concentrate (\%) & & & & & \\
MO (OM) & 96,18 & 95,98 & 95,81 & 95,58 & 95,40 \\
PB (CP) & 12,68 & 13,09 & 13,01 & 13,24 & 12,74 \\
EE & 3,33 & 2,91 & 2,35 & 1,83 & 1,31 \\
FDN (NDF) & 34,70 & 34,08 & 36,63 & 37,19 & 39,29 \\
FDA (ADF) & 18,78 & 19,35 & 22,20 & 28,42 & 26,23 \\
CHO (CHO) & 79,70 & 79,38 & 80,44 & 80,50 & 81,35 \\
CNF (NFC) & 45,00 & 45,29 & 43,81 & 43,33 & 42,05 \\
Ca & 0,42 & 0,46 & 0,46 & 0,44 & 0,46 \\
P & 0,22 & 0,24 & 0,22 & 0,23 & 0,22 \\
\hline
\end{tabular}

substituição do milho, $2=25 \%, 3=50 \%, 4=75 \%$ e $5=100 \%$ de substituição do milho pelo resíduo de mandioca); $\stackrel{\circ}{\mathrm{ij}}_{\mathrm{ij}}=$ erro aleatório.

\section{Resultados e Discussão}

O consumo de MS (CMS), em porcentagem do peso corporal (Tabela 4), não foi influenciado pela substituição do milho pelo resíduo de mandioca, com média de 1,98\%. Os valores encontrados foram inferiores aos determinados por Lorenzoni \& Mella (1994), que substituíram o milho pelo resíduo da lavagem das raízes e registraram consumo de $2,66 \%$ do peso corporal.

Os coeficientes de digestibilidade de MS, PB, EE, FDN, FDA, CHO, CNF e a porcentagem de NDT e EM, em Mcal $/ \mathrm{kg}$, das dietas encontram-se na Tabela 4.

A substituição do milho pelo resíduo de fecularia não influenciou o CDMS $(\mathrm{P}>0,05)$ das dietas, sendo determinado valor médio de $65,42 \%$. Embora não tenha ocorrido diferença entre os tratamentos, as dietas com maiores porcentagens de substituição apresentaram maiores valores absolutos $(71,42 \%$ para a dieta com substituição total), provavelmente em virtude da maior inclusão do resíduo, que, em razão das características de seu amido, apresenta maior degradabilidade e digestibilidade que o milho (Caldas Neto et al., 2000).

Jorge et al. (2002) também observaram aumento no CDMS e do amido quando substituíram o milho por farinha de varredura. Considerando os valores determinados por Martins et al. (2000), de 49,2\% para a dieta com milho como fonte de energia e $63,3 \%$ para a dieta com casca de mandioca, os valores obtidos neste experimento para a dieta com milho ou com substituição total pelo resíduo são superiores, provavelmente em razão da maior proporção de concentrado e da qualidade dos componentes das dietas (Tabela 3). 
Tabela 4 - Consumo de MS (CMS), em \% do peso corporal, coeficientes de digestibilidade (\%) de MS (CDMS), PB (CDPB), EE (CDEE), FDN (CDFDN), FDA (CDFDA), CHO (CDCHO) e CNF (CDCNF), porcentagens de NDT e EM, em Mcal/kg, coeficientes de variação $(\mathrm{CV}, \%)$ e equações de regressão (ER)

Table 4 - DM intake as \% of body weight (DMI), apparent digestibility coefficients (\%) of DM (DMDC), CP (CPDC), EE (EEDC), NDF (NDFDC), ADF (ADFDC), $T C(C H O D C)$, and NFC (NFCDC), contents of TDN and metabolizable energy (ME), in Mcal/kg, of the experimental diets, coefficients of variation $(\mathrm{CV}, \%)$ and regression equations (RE)

\begin{tabular}{|c|c|c|c|c|c|c|c|}
\hline \multirow[b]{2}{*}{$\begin{array}{l}\text { Variável } \\
\text { Item }\end{array}$} & \multicolumn{5}{|c|}{$\begin{array}{l}\text { Dieta/ \% de substituição } \\
\text { Diet/\% of replacement }\end{array}$} & \multirow[b]{2}{*}{$\mathrm{CV} \%$} & \multirow[b]{2}{*}{$\begin{array}{l}\mathrm{ER} \\
R E\end{array}$} \\
\hline & 0 & 25 & 50 & 75 & 100 & & \\
\hline CMS (DMI) & 1,99 & 1,99 & 1,99 & 1,97 & 1,97 & 4,12 & $\hat{\mathrm{Y}}=1,98$ \\
\hline CDMS (DMDC) & 63,78 & 61,34 & 65,05 & 65,49 & 71,42 & 5,92 & $\hat{\mathrm{Y}}=65,42$ \\
\hline $\mathrm{CDPB}(C P D C)$ & 69,10 & 64,77 & 68,04 & 67,61 & 71,97 & 6,05 & $\hat{\mathrm{Y}}=68,30$ \\
\hline CDFDA $(A D F D C)$ & 47,06 & 46,71 & 52,60 & 51,76 & 55,43 & 8,78 & $\hat{\mathrm{Y}}=50,71$ \\
\hline $\mathrm{CDCHO}(\mathrm{CHODC})$ & 64,16 & 61,64 & 65,73 & 66,30 & 72,14 & 6,50 & 1 \\
\hline CDCNF (NFCDC) & 76,83 & 76,08 & 78,51 & 89,07 & 89,36 & 9,35 & $\hat{\mathrm{Y}}=81,97$ \\
\hline $\mathrm{NDT}(T D N)$ & 64,91 & 63,22 & 64,73 & 64,67 & 69,43 & 5,99 & $\hat{\mathrm{Y}}=65,39$ \\
\hline $\mathrm{EM}(M E)$ & 2,34 & 2,28 & 2,34 & 2,34 & 2,51 & 5,99 & $\hat{\mathrm{Y}}=2,36$ \\
\hline
\end{tabular}

$1 \hat{\mathrm{Y}}=63,756-0,0684 \mathrm{~N}+0,0015 \mathrm{~N}^{2} ; \mathrm{R}^{2}=0,9122(\mathrm{P}<0,05)$.

$\mathrm{N}=\%$ de substituição na dieta (\% of replacement on diet).

Avaliando o mesmo subproduto, Ramos et al. (2000) não notaram diferença no CDMS para a substituição do milho pelo bagaço de mandioca e determinaram valor médio de $62,9 \%$ na dieta (considerado baixo), atribuído à baixa qualidade do volumoso utilizado. No entanto, Marques et al. (2000) compararam dietas com casca de mandioca, farinha de varredura e raspa de mandioca e verificaram CDMS de 63,$1 ; 63,1$ e 73,2\%, próximos aos registrados neste ensaio. Considerando o valor observado, pode-se inferir que o CDMS foi elevado em função da proporção de concentrado na dieta (Tabela 3), da alta digestibilidade dos componentes dos concentrados e da qualidade da silagem utilizada (Tabela 1).

O CDPB não foi influenciado pelos níveis de substituição ( $\mathrm{P}>0,05)$, verificando-se média de $68,30 \%$ para as dietas. Contudo, o CDPB da dieta com $100 \%$ de resíduo foi elevado (71,97\%). Como a porcentagem de proteína no resíduo de fecularia é muito baixa (Tabela 1), a substituição do milho pelo resíduo ocasionou aumento da inclusão do farelo de soja e da uréia nas dietas com maiores proporções de substituição (Tabelas 2 e 3). Desse modo, o CDPB pode ter sido influenciado pelo aumento do teor de nitrogênio nãoprotéico das dietas com maiores porcentagens de substituição, que, combinado com elevados teores de carboidratos de alta degradabilidade, confirmariam os dados descritos por Jorge et al. (2002), que observaram incremento na digestibilidade da proteína nos maiores níveis de substituição do milho pela farinha de varredura. $\mathrm{O}$ aumento da participação do farelo de soja nestas dietas, em substituição à proteína do milho, pode ter contribuído para esse acréscimo, pois, conforme Castilho et al. (1993), a degradabilidade da proteína da soja é superior à do milho.

O CDEE foi semelhante entre os tratamentos ( $\mathrm{P}>0,05)$, com valor médio de $67,72 \%$, que são superiores aos citados por Lançanova et al. (2001), que avaliaram uma dieta com $1,2 \%$ de EE ofertada a animais de diferentes raças e obtiveram CDEE médio de $44,42 \%$, atribuído ao baixo nível de EE na dieta e ao efeito da fração endógena desse componente sobre o coeficiente de digestibilidade aparente, como relataram Silva \& Leão (1979). Neste ensaio, a porcentagem do EE na dieta com $100 \%$ de resíduo foi reduzida (1,31\%, Tabela 3 ), em comparação às demais, o que pode ter influenciado o CDEE para essa dieta, sugerindo algum efeito do EE endógeno.

Não houve efeito $(\mathrm{P}>0,05)$ da substituição do milho pelo resíduo de fecularia sobre o CDFDN e o CDFDA (49,58 e $50,71 \%$, respectivamente). O CDFDN obtido foi próximo ao determinado por Zeoula et al. (2003), que avaliaram quatro níveis de substituição do milho pela farinha de varredura em dietas com 45 a $50 \%$ de concentrado e não observaram diferença entre os tratamentos (média de $55,90 \%$ ). Em trabalho realizado por Jorge et al. (2002), a inclusão de níveis crescentes de farinha de varredura em dietas para bezerros também não alterou o CDFDN (valor médio de 52,34\%). Contudo, neste ensaio, a proporção de concentrado na dieta foi de $80 \%$ e os valores de carboidratos prontamente fermentáveis (amido) variaram de 47,10 a $52,40 \%$ da $\mathrm{MS}$, o que poderia comprometer o ambiente ruminal e a conseqüente degradação da fração fibrosa. Maiores variações no CDFDN foram observadas por Marques et al. (2000), que registraram valores de CDFDN de 32,90\% 
para a dieta com farinha de varredura e $57,60 \%$ para a dieta com raspa de mandioca.

De forma semelhante ao CDFDN, o CDFDA também não foi influenciado pelos tratamentos. O CDFDA médio de $50,71 \%$ aproxima-se dos valores reportados por Marques et al. (2000), de 49,60\% para dietas com casca de mandioca e $54,90 \%$ para dietas com raspa de mandioca ( $60 \%$ de concentrado e $40 \%$ de volumoso). Ramos et al. (2000) também não notaram diferença para o CDFDA entre os níveis de substituição avaliados e determinaram valor médio de $50,49 \%$ para a fração FDA. Lorenzoni \& Mella (1994), no entanto, avaliaram a substituição do milho pelo resíduo sólido da lavagem das raízes de mandioca como suplemento energético e verificaram redução significativa no CDFDA para a dieta com substituição total do rolão de milho $(31,68 \%)$, comparada àquela com o milho $(43,19 \%)$ ou com substituição de 33\% do milho pelo resíduo (40,52\%). Esses autores atribuíram essa redução ao aumento da lignina nas dietas com maior participação do resíduo de mandioca.

O CDCHO apresentou relação quadrática $(\mathrm{P}<0,05)$ com as crescentes porcentagens de substituição do milho pelo resíduo de fecularia, observando-se pequena redução para a dieta com $25 \%$ de resíduo e aumento nas porcentagens subseqüentes (Tabela 4), conseqüência dos valores de CDFDN e CDCNF, que, juntos, originam o CDCHO (Tabela 3). Portanto, a substituição do milho pelo resíduo de mandioca não alterou os teores de CNF das dietas, mas ocasionou a substituição dos carboidratos do milho pelos da mandioca. Como quase todos os carboidratos presentes no milho e na mandioca são representados pelo amido, os subprodutos da mandioca possuem composição de CNF semelhante ao milho. Segundo Cereda (1994), dos carboidratos não-fibrosos (CNF) do resíduo da extração da fécula, apenas $0,01 \%$ da MS está sob a forma de carboidratos solúveis, sendo o restante amido. Apesar da pequena variação no teor de CNF e da conseqüente variação reduzida no teor de amido, a composição do amido dessas duas fontes é bastante diferente, pois, de acordo com Caldas Neto et al. (2000), o amido de mandioca é composto principalmente por cadeias de amilopectina, enquanto o do milho possui menor proporção desta cadeia em relação ao da mandioca. Além disso, a não-associação dos grãos de amido com a matriz protéica, na mandioca, pode influenciar positivamente a digestibilidade do amido, visto que, no milho, essa associação tem influência negativa (Pires, 1999).

A substituição do milho pelo resíduo de mandioca não influenciou $(\mathrm{P}>0,05)$ os valores de NDT e EM das dietas (Tabela 4), que apresentaram valores médios de $65,47 \% \mathrm{e}$ $2,36 \mathrm{Mcal} / \mathrm{kg}$. Entretanto, o maior valor absoluto para o NDT
$(69,43 \%)$ foi determinado para a dieta com substituição total do milho pelo resíduo de mandioca e foi superior ao da dieta com $25 \%$ de substituição em $9,8 \%$ ou 6,2 unidades percentuais de NDT. Os valores para NDT e EM determinados neste ensaio são próximos aos encontrados por Jorge et al. (2002), ao avaliarem a substituição do milho pela farinha de varredura $(66,60$ e $71,10 \%$ para o NDT e 2,41 e $2,53 \mathrm{Mcal} / \mathrm{kg}$ de EM para as dietas com milho e com $100 \%$ de farinha de varredura). Nesse mesmo estudo, esses autores encontraram efeito linear positivo da porcentagem de substituição do milho pela farinha de varredura sobre o coeficiente de digestibilidade da EB. Marques et al. (2000) também avaliaram diferentes subprodutos de mandioca e obtiveram coeficientes de digestibilidade da EB que, aplicados aos valores de energia determinados para as dietas à base de milho e farinha de raspas de mandioca, forneceram valores de NDT de 54 e $70 \%$ e de EM de 1,99 e 2,54 Mcal/kg. Estes menores valores de NDT e EM para a dieta com milho, em comparação aos da dieta à base de raspa de mandioca, confirmam os obtidos neste experimento, em que se observou maior valor energético para a dieta com substituição total do milho pelo resíduo de mandioca (Tabela 4), confirmado pela maior digestibilidade dos componentes do resíduo, principalmente os CNF.

\section{Conclusões}

A inclusão do resíduo úmido da extração da fécula de mandioca em substituição ao milho como concentrado energético, apesar da elevada digestibilidade da matéria seca e dos carboidratos não-fibrosos, não influenciou o coeficiente de digestibilidade dos componentes avaliados, à exceção dos carboidratos totais.

\section{Literatura Citada}

AGRICULTURAL AND FOOD RESEARCH COUNCIL - AFRC. Technical committee on responses to nutrients: energy and protein requirements of ruminants. Wallingford: $C A B$ International, 1993. 159p.

CALDAS NETO, S.F; ZEOULA, L.M.; BRANCO, A.F. et al. Mandioca e resíduos das farinheiras na alimentação de ruminantes: digestibilidade total e parcial. Revista Brasileira de Zootecnia, v.29, n.6 (sup.1), p.2099-2108, 2000.

CAMPOS NETO, O.; DE BEM, C.H.W. Mandioca. In: SIMPÓSIO SOBRE NUTRIÇÃO DE BOVINOS: UTILIZAÇÃO DE RESÍDUOS CULTURAIS E DE BENEFICIAMENTO NA ALIMENTAÇÃO DE BOVINOS, 6., 1995, Piracicaba. Anais... Piracicaba: Fundação de Estudos Agrários Luiz de Queiroz, 1995. p.215-228.

CASTILHO, A.A.M.; VALADARES FILHO, S.C.; COELHO DA SILVA, J.F. et al. Degradabilidade ruminal da matéria seca e da proteína bruta de alimentos, utilizando a técnica do saco de náilon, em vacas gestantes alimentadas com feno (80\%) e 
concentrados $(20 \%)$. Revista da Sociedade Brasileira de Zootecnia, v.22, n.1, p.89-98, 1993.

CASTRO, M.E.D.; COELHO DA SILVA, J.F. Substituição do milho desintegrado com palha e sabugo pela raspa de mandioca integral em rações para ruminantes. II. Confinamento de bovinos. Experientiae, v.2. n.1, p.59-68, 1994.

CEREDA, M.P. Caracterização dos resíduos da industrialização da mandioca. In: CEREDA, M.P. (Ed.) Resíduos da industrialização da mandioca. Botucatu: Paulicéia, 1994. p.11-50.

HALL, M.B. Recent advances in non-NDF carbohydrates for the nutrition of lactating cows. In: SIMPÓSIO INTERNACIONAL EM BOVINOCULTURA DE LEITE: NOVOS CONCEITOS EM NUTRIÇÃO, 2., 2001, Lavras. Anais... Lavras: Universidade Federal de Lavras, 2001. p.139-148.

JORGE, J.R.V.; ZEOULA, L.M.; PRADO, I.N. et al. Substituição do milho pela farinha de varredura (Manhiot esculenta, Crantz) na ração de bezerros holandeses. 2. Digestibilidade e valor energético. Revista Brasileira de Zootecnia, v.31, n.1, p.205-212, 2002.

LANÇANOVA, J.A.C.; OLIVEIRA, M.D.S. ; PACOLA, L.J. et al. Digestibilidade aparente da proteína e dos componentes da parede celular de uma ração completa, com bovinos de diferentes grupos genéticos. Revista Brasileira de Zootecnia, v.30, n.6, p.19131918, 2001.

LORENZONI, W.R.; MELLA, S.C. Avaliação do resíduo obtido da lavagem de raiz de mandioca como alimento energético para bovinos. In: CEREDA, M.P. (Ed.) Resíduos da industrialização da mandioca. Botucatu: Paulicéia, 1994. p.91-100.

MARQUES, J.A.; PRADO, I.N.; ZEOULA, L.M. et al. Avaliação da mandioca e seus resíduos industriais em substituição ao milho no desempenho de novilhas confinadas. Revista Brasileira de Zootecnia, v.5, n.5 p.1528-1536, 2000.

MARTINS, A.S.; PRADO, I.N.; ZEOULA, M.L. et al. Digestibilidade aparente de dietas contendo milho ou casca de mandioca como fonte energética e farelo de algodão ou levedura como fonte protéica em novilhas. Revista Brasileira de Zootecnia, v.29, n. 1, p.269-277, 2000 .

MELLOTI, L. Contribuição para o estudo da composição química e valor nutritivo dos resíduos da industrialização da mandioca, Manhiot utilíssima, Pohl., no estado de São Paulo. Boletim da Industria Animal, v.29, n.2, p.339-349, 1972.
NATIONAL RESEARCH COUNCIL - NRC. Nutrients requirements of beef cattle. 7.ed. Washington, D.C.: National Academy Press, 1996. 244p.

PIRES, A.V. Efeito da inclusão de fontes de amido e silagem de milho em dietas à base de cana-de-açucar na digestibilidade de nutrientes e na produção de leite de vacas Holandesa. Piracicaba: Escola Superior de Agricultura Luiz de Queiroz, 1999. 120p. Tese (Livre Docente em Produção Animal) - Escola Superior de Agricultura Luiz de Queiroz, 1999.

RAMOS, P.R.; PRATES, E.R.; FONTANELLI, R.S. et al. Uso do bagaço de mandioca em substituição ao milho no concentrado para bovinos em crescimento. 2. Digestibilidade aparente, consumo de nutrientes digestíveis, ganho de peso e conversão alimentar. Revista Brasileira de Zootecnia, v.29, n.1, p.300-305, 2000 .

COELHO DA SILVA, J.F.; LEÃO, M.I. Fundamentos de nutrição de ruminantes. Piracicaba: Livroceres, 1979. 380p.

SILVA, D.J.; QUEIROZ, A.C. Análise de alimentos, métodos químicos e biológicos. 3.ed. Viçosa, MG: Universidade Federal de Viçosa, 2002. 235p.

SNIFFEN, C.J.; O'CONNOR, J.D.; Van SOEST, P.J. et al. A net carbohydrate and protein availability. Journal of Animal Science, v.70, n.11, p.3562-3577, 1992.

UNIVERSIDADE FEDERAL DE VIÇOSA - UFV. SAEG - Sistema de Análises Estatísticas e Genéticas.Versão 7.1. Viçosa, 1997. 150p. (Manual do usuário).

ZEOULA, M.L.; MARTINS, A.S.; ALCALDE, C.R. et al. Solubilidade e degradabilidade do amido de diferentes alimentos. Revista Brasileira de Zootecnia, v.28, n.5, p.905-912, 1999.

ZEOULA, M.L.; PRADO, I.N.; CALDAS NETO, S.F. et al Substituição do milho pela farinha de varredura de mandioca (Manihot esculenta Crantz) em rações de ovinos: consumo, digestibilidade, balanço de nitrogênio e energia e parâmetros ruminais. Revista Brasileira de Zootecnia, v.32, n.2, p.491-502, 2003 . 